\title{
TCL1 Oncogene Expression in B Cell Subsets from Lymphoid Hyperplasia and Distinct Classes of B Cell Lymphoma
}

\author{
Jonathan W. Said, Katrina K. Hoyer, Samuel W. French, Lisa Rosenfelt, \\ Maria Garcia-Lloret, Patricia J. Koh, Tse-Chang Cheng, Girija G. Sulur, \\ Geraldine S. Pinkus, W. Michael Kuehl, David J. Rawlings, Randolph Wall, and \\ Michael A. Teitell
}

Department of Pathology and Laboratory Medicine (JWS, KKH, SWF, LR, TCC, GGS, MAT), Department of Pediatrics (MG-L, DJR), and Jonsson Comprehensive Cancer Center (DJR, RW, MAT), University of California at Los Angeles School of Medicine, and Department of Microbiology and Immunology (PJK, RW) and Molecular Biology Institute (DJR, RW, MAT), University of California at Los Angeles, Los Angeles, California; Department of Pathology (GSP), Brigham and Woman's Hospital, Harvard Medical School, Boston, Massachusetts; and Genetics Department (WMK), Medicine Branch, National Cancer Institute, Bethesda, Maryland

\begin{abstract}
SUMMARY: Activation of the TCL1 oncogene has been implicated in T cell leukemias/lymphomas and recently was associated with AIDS diffuse large B cell lymphomas (AIDS-DLBCL). Also, in nonmalignant lymphoid tissues, antibody staining has shown that mantle zone B cells expressed abundant Tcl1 protein, whereas germinal center (GC; centrocytes and centroblasts) B cells showed markedly reduced expression. Here, we analyze isolated B cell subsets from hyperplastic tonsil to determine a more precise pattern of Tcl1 expression with development. We also examine multiple B cell lines and B lymphoma patient samples to determine whether different tumor classes retain or alter the developmental pattern of expression. We show that TCL1 expression is not affected by Epstein-Barr virus (EBV) infection and is high in naïve B cells, reduced in GC B cells, and absent in memory $B$ cells and plasma cells. Human herpesvirus-8 infected primary effusion lymphomas (PEL) and multiple myelomas are uniformly TCL1 negative, whereas all other transformed B cell lines tested express moderate to abundant TCL1. This observation supports the hypothesis that PEL, like myeloma, usually arise from post-GC stages of B cell development. Tcl1 protein is also detected in most naïve/GC-derived B lymphoma patient samples (23 of 27 [85\%] positive), whereas most post-GC-derived B lymphomas lack expression (10 of 41 [24\%] positive). These data indicate that the pattern of Tcl1 expression is distinct between naïve/GC and post-GC-derived $\mathrm{B}$ lymphomas $(P<0.001)$ and that the developmental pattern of expression is largely retained. However, post-GC-derived AIDS-DLBCL express TCL1 at a frequency equivalent to naïve/GC-derived B lymphomas in immunecompetent individuals (7 of 9 [78\%] positive), suggesting that TCL1 down-regulation is adversely affected by severe immune system dysfunction. These findings demonstrate that TCL1 expression in B cell lymphoma usually reflects the stage of B cell development from which they derive, except in AIDS-related lymphomas. (Lab Invest 2001, 81:555-564).
\end{abstract}

$T$ cell leukemias/lymphomas in adults and in children with the genomic instability syndrome ataxia telangiectasia have repeated rearrangements on chromosome 14q32.1 (Davey et al, 1988; Mengle-Gaw et al, 1988; Russo et al, 1988; Virgilio et al, 1993). Analysis of a $160-k b$ region on $14 q 32.1$ that is bracketed by two breakpoint clusters led to the identification of a candidate tumor-promoting gene, TCL1 (Virgilio et al, 1994).

Received December 22, 2000.

This study was supported by the Amgen/U.C. BioSTAR Project (S98-35), Lymphoma Research Foundation of America, Jonsson Comprehensive Cancer Foundation, and National Institutes of Health (CA74929, GM40185, CA85841, and CA66533).

Address reprint requests to: Dr. Michael A. Teitell, Department of Pathology and Laboratory Medicine, Center for the Health Sciences, UCLA School of Medicine, 10833 Le Conte Ave., Los Angeles, California 90095 1732.E-mail:mteitell@ucla.edu 14q32.1 chromosomal rearrangements reposition $\mathrm{T}$ cell receptor control elements at $7 q 35$ or $14 q 11$ near the TCL1 coding region, resulting in abnormal gene activation in T cell malignancies. Recently, the Tcl1 oncoprotein was found by coimmunoprecipitation and yeast two-hybrid studies to interact with the essential serine/ threonine kinase Akt (Laine et al, 2000; Pekarsky et al, 2000). These studies indicated that Tcl1 activates Akt, resulting in increased phosphorylation of Akt-target proteins, enhanced cell proliferation and survival, and Akt nuclear relocalization. These findings provide a mechanism for Tcl1-dependent $\mathrm{T}$ cell transformation through inappropriate Akt pathway activation. It is unknown if aberrant Tcl1 expression also induces B cell malignancies as well.

In an initial survey of B cells, TCL1 expression was shown primarily in bone marrow and in endemic, Epstein-Barr virus (EBV)-positive Burkitt lymphoma 
(BL) cell lines (Virgilio et al, 1994). However, a subsequent study yielded data that also showed TCL1 expression by mature peripheral B cells (PBC) (Takizawa et al, 1998). With regard to EBV infection, this second study did not assess the EBV status of PBC, and more than $90 \%$ of individuals worldwide are known to harbor latent EBV (Westphal et al, 1999). Complicating this picture was a report that immortalization of PBC with EBV yielded clones that were uniformly TCL1-positive (Pekarsky et al, 1999). The combined data suggested that EBV infection might positively influence TCL1 expression in PBC and BL.

We recently investigated normal, nonmalignant TCL1 expression in reactive lymphoid tissues by immunohistochemistry (Teitell et al, 1999). We found that nonproliferating mantle zone $\mathrm{B}$ cells expressed very high levels of Tcl1 protein, whereas germinal center (GC) B cells showed markedly reduced levels of expression. In addition, a large majority of interfollicular zone lymphocytes failed to express Tcl1. This specific pattern of Tcl1 expression suggested that B cell lymphomas derived from distinct follicular zones would express characteristic levels of Tcl1, whereas post-GC B cell lymphomas would likely not express Tcl1. However, we also identified Tcl1 expression in an EBV-negative, AIDS diffuse large B cell lymphoma (AIDS-DLBCL) by subtractive gene hybridization (Teitell et al, 1999). An extended survey of patient tumor tissues showed that a majority of AIDS-DLBCL expressed TCL1 (6 of 8 [75\%] positive). AIDS-DLBCL arise from post-GC B cells and our observation suggested that TCL1 may be expressed aberrantly and have a role in tumor development. Because EBV status did not correlate with Tcl1 expression in AIDSDLBCL, it is possible that the functional status of the immune system has a role in TCL1 regulation and that $B$ cell transformation is augmented by or affects Tcl1 expression.
Here, we investigate TCL1 expression in normal B cells, nontransformed and transformed B cell lines, and in a wide spectrum of patient-derived $B$ cell malignancies from immune-competent individuals. This study was prompted by our immunohistochemical findings that suggested that post-GC B lymphocytes exhibit down-regulation of Tcl1 expression, whereas AIDS-DLBCL appear to retain or re-express Tcl1 (Teitell et al, 1999). The main question addressed is whether Tcl1 expression is altered in distinct classes of B lymphoma and therefore could potentially contribute to malignant transformation in immunecompetent and immune-deficient individuals.

\section{Results}

\section{TCL1 Expression is Independent of EBV Infection in B Cell Lines}

Northern analyses of TCL1 expression were performed on immortalized and transformed B cell tumor lines containing or lacking EBV. The data show that TCL1 levels remain stable with or without EBV infection of endemic or sporadic BL (Fig. 1 and Table 1). In addition, lack of EBV-encoded major oncoproteins EBNA-2 and LMP1 did not abolish TCL1 expression in the P3HR-1 BL line (Miller et al, 1974). Establishment of a mature immune system, with reactive secondary $\mathrm{GC}$, is not required for TCL1 expression in circulating PBC, inasmuch as 9 of 9 immortalized fetal cord B cell lines and 6 of 6 immortalized PBC from normal adults express abundant TCL1 (Ounanian et al, 1992; Pekarsky et al, 1999). Furthermore, four primary effusion lymphomas (PEL) lines (and two PEL patient samples) failed to express TCL1 regardless of EBV infection (Fig. 1, Table 1, and data not shown). Overall, the data show that a mature immune system is not required for Tcl1 expression and that EBV infection is not associ-

A

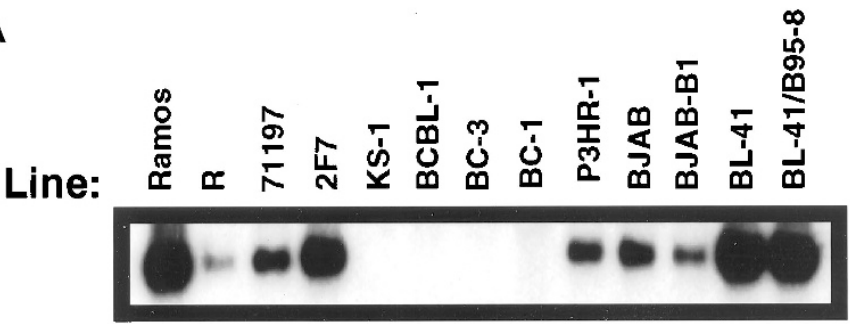

EBV: $++++\cdots+++-++$

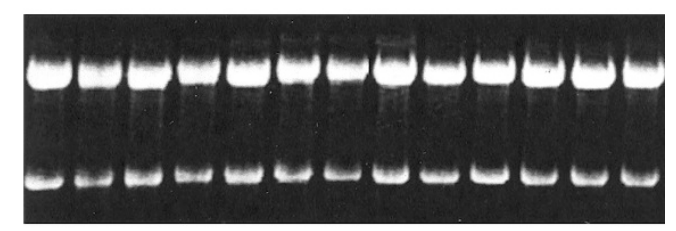

Fold: $\begin{array}{lllllllllllll}23.6 & 1.0 & 2.7 & 11.7 & 0 & 0 & 0 & 0 & 2.1 & 2.8 & 1.5 & 25.6 & 24.1\end{array}$

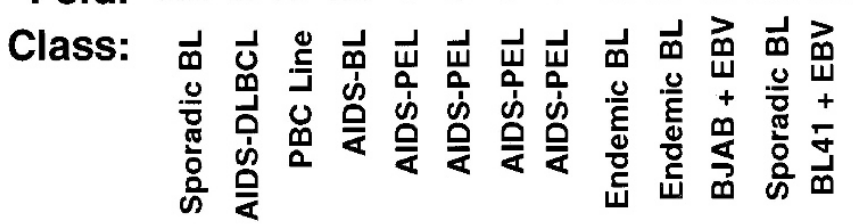

Figure 1.

TCL1 mRNA expression in B cell lines is independent of Epstein-Barr virus (EBV) status. A, Northern analysis of TCL1 expression. Fold-induction is determined by Phosphorimager analysis, and the values listed are relative to an arbitrarily set value of 1.0 for the AIDS diffuse large $B$ cell lymphoma (AIDS-DLBCL) cell line R. EBV status is derived from published reports. $B L$, Burkitt lymphoma; $D L B C L$, diffuse large B cell lymphoma; $P B C$, peripheral $B$ cell; $P E L$, primary effusion lymphoma. $B$, Ethidium bromide stained formaldehyde gel showing equal lane loading of total RNA from $B$ cell lines. 
Table 1. Relative TCL1 mRNA Expression Levels in Immortalized and Transformed B and T Cell Lines ${ }^{a}$

\begin{tabular}{|c|c|c|c|c|c|c|}
\hline Category & $\begin{array}{c}\text { Line } \\
\text { Designation }\end{array}$ & Classification & $\begin{array}{l}\text { HHV-8 } \\
\text { Status }\end{array}$ & $\begin{array}{l}\text { EBV } \\
\text { Status }\end{array}$ & $\lg$ & $\begin{array}{l}\text { TCL1 } \\
\text { (Fold) }\end{array}$ \\
\hline \multirow{2}{*}{$\begin{array}{l}\text { Immortalized } \\
\text { lines }\end{array}$} & Fetal cord & $\mathrm{n}=9$ & - & + & + & $1.0-23.8$ \\
\hline & PBC & $\mathrm{n}=6$ & - & + & + & $2.7-10.8$ \\
\hline \multirow{9}{*}{$\begin{array}{l}\text { Burkitt } \\
\text { lymphoma } \\
\text { lines }\end{array}$} & BL41 & Sporadic & - & - & + & 25.6 \\
\hline & BL41/B95-8 & EBV-infected & - & + & + & 24.1 \\
\hline & BJAB & Endemic & - & - & + & 2.8 \\
\hline & BJAB/B1 & EBV-infected & - & + & + & 1.5 \\
\hline & Akata A1.5 & Sporadic & - & - & + & 5.7 \\
\hline & Akata 2A8 & EBV-infected & - & + & + & 5.3 \\
\hline & Akata 3F2 & EBV-infected & - & + & + & 5.8 \\
\hline & Ramos & Sporadic & - & - & + & 23.6 \\
\hline & P3HR-1 & Endemic & - & + & + & 2.1 \\
\hline \multirow[t]{2}{*}{ AIDS lines } & $2 \mathrm{~F} 7$ & $B L$ & - & + & + & 11.7 \\
\hline & $\mathrm{R}$ & DLBCL & - & + & + & 1.0 \\
\hline \multirow[t]{4}{*}{ PEL lines } & KS-1 & & + & - & - & 0 \\
\hline & $B C-1$ & & + & + & - & 0 \\
\hline & BC-3 & & + & - & - & 0 \\
\hline & BCBL-1 & & + & - & - & 0 \\
\hline Myeloma & Various & $n=29$ & - & ND & ND & 0 \\
\hline \multirow[t]{2}{*}{ T cell lines } & Jurkat & T-ALL & - & - & - & 0 \\
\hline & CEM & T-ALL & - & - & - & 0 \\
\hline Myeloid line & K562 & CML & - & - & - & 0 \\
\hline
\end{tabular}

BL, Burkitt lymphoma; DLBCL, diffuse large B cell lymphoma; ALL, acute lymphoblastic leukemia; CML, chronic myelogenous leukemia; ND, not determined. ${ }^{a}$ Summary of cell lines examined, HHV-8 and EBV status, Ig production, and Northern analysis for TCL1 gene expression. HHV-8, EBV, and Ig values were obtained from published reports except for fetal cord and PBC lines (Benjamin et al, 1982; Demidem et al, 1996; Miller and Lipman, 1973; Ruf et al, 1999). Nine fetal cord, 6 PBC, and 29 myeloma cell lines were surveyed for TCL1 expression. The myeloma lines used here have been described previously (Shou et al, 2000). P3HR-1 is an endemic BL that lacks major EBV oncoproteins EBNA-2 and LMP1. The data for TCL1 RNA expression is presented as a relative level of expression over the arbitrarily set value of 1.0 for cell line $\mathrm{R}$ (Fig. 1).

ated with nor does it affect Tcl1 expression in transformed B cell lines.

\section{PEL and Myeloma Transformed Cell Lines Do Not Express Tcl1}

PEL are a unique and rare category of immunodeficiencyrelated lymphoma that almost always contain human herpesvirus-8 and are most often associated with advanced stages of AIDS (Drexler et al, 1998; Jones et al, 1998). PEL mainly are considered a GC- or post-GCderived $B$ lymphoma because of their variable large cell morphology, frequent activation marker expression, and productive rearrangements of their nonexpressed immunoglobulin genes with evidence of somatic hypermutation (Drexler et al, 1998; Matolcsy et al, 1998). However, the AIDS-related PEL line BC-3 recently has been shown to lack evidence of immunoglobulin gene mutations, suggesting that this PEL may originate from a naiive/pre-GC rather than a GC or post-GC B cell precursor (Matolcsy et al, 1998). The pattern of Tcl1 expression, therefore, was assessed in four different PEL lines (and in two PEL patient samples) in an attempt to provide additional insight into the derivation of this unusual lymphoma subclass. In 6 of 6 cases, including the BC-3 PEL cell line, Tcl1 expression was not detected (Fig. 1, Table 1, and not shown). This pattern most closely resembles an earlier report of negative Tcl1 expression in post-GC and terminally differentiated myeloma cell lines (Takizawa et al, 1998). To confirm and extend this earlier reported expression pattern into patient tumor samples, we assessed an additional 29 myeloma cell lines, along with three patient-derived myeloma tissues, and all were found to be negative for Tcl1 expression (Table 1 , and not shown).

\section{Tcl1-Expression in Normal Peripheral B Cells Depends on Developmental Stage}

Previous antibody staining of lymphoid tissues suggested a developmental stage-dependent change in Tcl1 expression in B cells (Teitell et al, 1999). To clearly define Tcl1 expression levels in B cell subsets, we isolated distinct populations from reactive human tonsils by a magnetic bead cell sorting system (MACS). Naïve B cells (CD10+/lgD+) express abundant Tcl1, whereas GC-derived B cells (CD10+/lgD-) express markedly reduced Tcl1 (19\% of naïve B levels), and memory B cells (CD10-/lgD-) and plasma cells (CD138+) do not express Tcl1 (Fig. 2). These findings are consistent with earlier immunohistochemistry results and indicate that scattered, interfollicular zone Tcl1 + cells are not post-GC B cells (Teitell et al, 
1999). Additional support for a staged downregulation in Tcl1 expression with $\mathrm{B}$ cell maturation was obtained with an in vitro coculture system in which CD19+ B cells are stimulated to differentiate into Ig-secreting plasmacytoid cells or plasmablasts (Fluckiger et al, 1998) (Fig. 2). MACS-isolated CD19+ tonsillar lymphocytes were cocultured with CD40Lexpressing $L$ cells in the presence of IL4 and IL10 and were harvested after 7 days. Wright-Giemsa staining demonstrated that these B cells had obtained plasmacytoid morphology, with eccentrically placed nuclei, abundant cytoplasm, and prominent perinuclear cytoplasmic hoffs. These cells also expressed detectable, albeit low, Tcl1 by Western blot $(4.2 \%$ of naïve $B$ levels). Overall, Western blot analysis of isolated B cell subsets refined the developmental pattern of Tcl1 expression and showed that expression is progressively down-regulated during final $B$ cell maturation in lymphoid tissues.
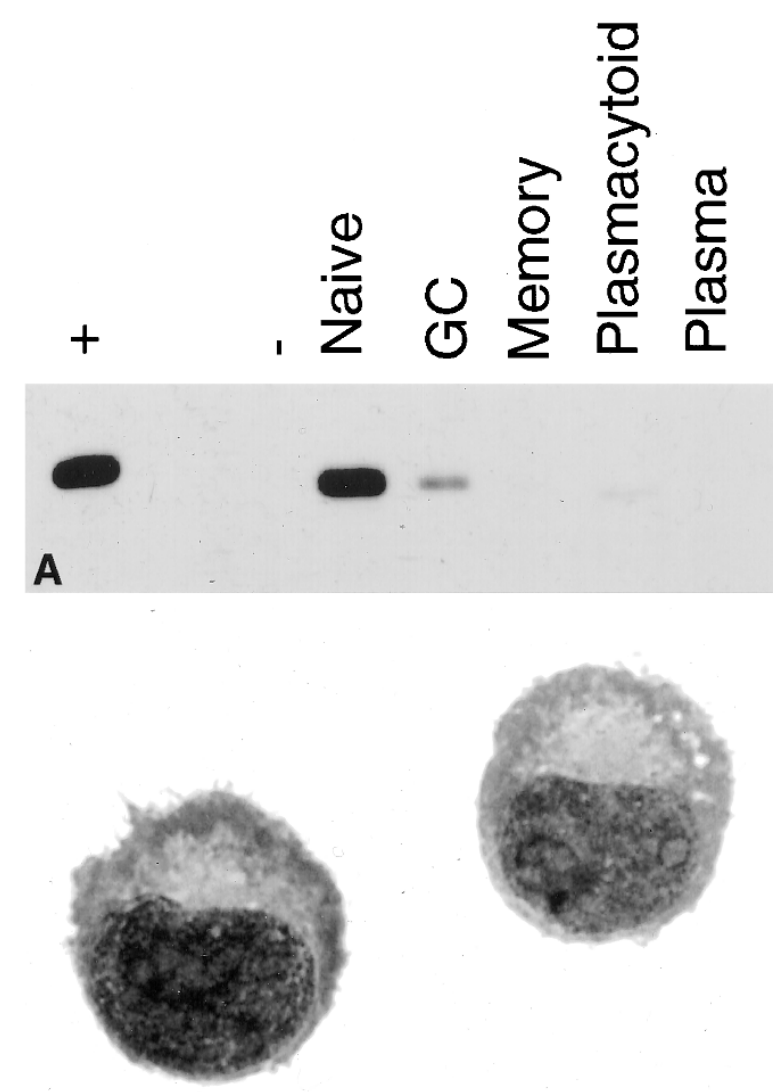

B

Figure 2.

Tcl1 protein expression varies with B cell developmental stage. A, Anti-Tcl1 Western blot analysis of isolated $B$ cell populations from human tonsil. P3HR-1 $(+)$ and BCBL-1 (-) control lysates are also shown. The level of Tcl1 expression seen in naïve $\mathrm{B}$ cells $(>90 \%$ pure, $\mathrm{CD} 10+/ \mathrm{lgD}+)$ was determined by densitometry and set arbitrarily at $100 \%$; this level is comparable to the P3HR-1 BL tumor cell line. Germinal center (GC) B cells ( $>85 \%$ pure, CD10+/lgD-) express $19 \%$ of the naiive $B$ cell level, whereas memory B cells (>95\% pure, CD10-/CD19+/lgD-) and plasma cells (CD138+) do not express Tcl1. Plasmacytoid B cells, grown on CD40L+ feeder cells supplemented with IL4 and IL10, express 4\% of the naive B cell level of TCl1. B, Wright-Giemsa stain of plasmacytoid B cells demonstrating characteristic morphologic features, including eccentric nuclear placement, abundant cytoplasm, and perinuclear hoff.

\section{Tcl1-Expression in Patient-Derived B Cell Lymphomas Also Depends on Developmental Stage}

Because EBV does not affect normal B cell expression of Tcl1, we investigated whether B cell lymphomas from immune-competent individuals retain Tcl1 expression in a pattern reflective of their developmental derivation. In this case, Tcl1 expression would represent a useful marker for the stage of differentiation of neoplastic B cells, particularly between GC and post-GC stages of development. In addition, TCL1 has known tumor-promoting capabilities in T cells and its expression may be indicative of a growth or survival advantage that may correlate with clinical aggressiveness, outcome, or mode of therapy in B cells. The results from Table 1 show that TCL1 is abundantly expressed in GC-derived BL but not in post-GCderived myeloma or PEL cell lines. To determine whether these cell line expression results are similar to results obtained from patients, we assessed the Tcl1 expression pattern in a large number and wide variety of tumor samples (Fig. 3 and Table 2).

In immune-competent individuals, the data show a marked transition in Tcl1 expression between naïve/GC and post-GC B cell lymphomas (Hummel et al, 1994). In 23 of 27 (85\%) cases naïve/GC-derived B lymphomas expressed abundant Tcl1, whereas only 16 of $41(39 \%)$ cases of post-GC B lymphomas were

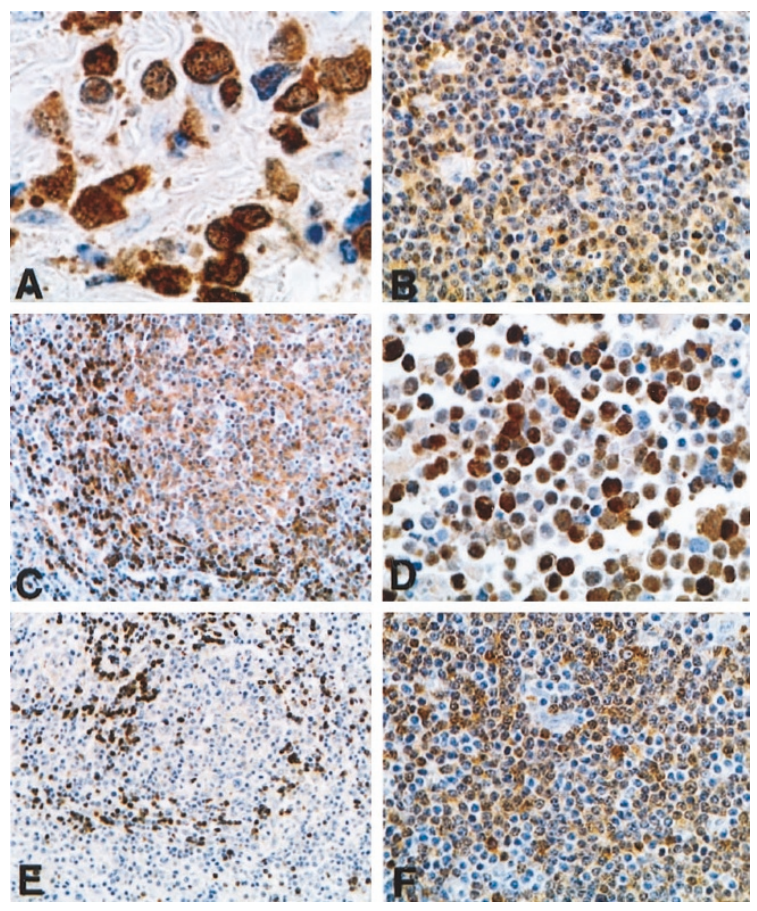

Figure 3.

Immunohistochemical staining of patient $B$ cell tumor samples with Tcl1 antisera. A, Lymphoblastic lymphoma, pre-B cell type, with strong $3+$ staining for Tcl1. B, Mantle cell lymphoma with 2+ staining for Tcl1. C, Follicle center cell lymphoma with $2+$ staining of the neoplastic follicle. The surrounding benign mantle cells are $3+$ positive. D, DLBCL with $3+$ staining for Tcl1. E, Marginal zone lymphoma negative for Tcl1. Strong staining is present in the residual mantle cells, which surround a follicle that has been colonized or replaced by a Tcl1-negative lymphoma. F, Marginal zone lymphoma with $2+$ staining for Tcl1. Hematoxylin counterstain. Original magnifications: $A, \times 600$; $B, C, D$, and $F, \times 250 ; E, \times 120$. 
Table 2. Tcl1 Protein Expression Levels in Patient-Derived B and T Cell Lymphomas ${ }^{a}$

\begin{tabular}{|c|c|c|c|}
\hline Tumor Classification & $\begin{array}{c}\text { Tcl1 }+ \text { Cases/No. } \\
\text { of Cases }\end{array}$ & $\begin{array}{l}\text { Tumor Cells } \\
+(\%)\end{array}$ & $\begin{array}{c}\text { Relative Level of Tcl1 } \\
\text { Expression }\end{array}$ \\
\hline \multicolumn{4}{|l|}{ Pre-B lymphoma } \\
\hline Lymphoblastic & $3 / 3$ & 90 & $3+$ \\
\hline \multicolumn{4}{|l|}{ Naïve/GC-derived B cell lymphoma } \\
\hline Mantle cell & $12 / 14$ & $70-95$ & $2+$ to $3+$ \\
\hline Follicular grade I & $7 / 7$ & $60-90$ & $1+$ to $3+$ \\
\hline Follicular grade II/III & $3 / 5$ & $80-100$ & $1+$ to $3+$ \\
\hline Burkitt lymphoma & $1 / 1$ & 90 & $3+$ \\
\hline \multicolumn{4}{|l|}{ Post GC-derived B cell lymphoma } \\
\hline Marginal zone & $4 / 10$ & $5-80$ & $2+$ to $3+$ \\
\hline \multicolumn{4}{|l|}{ Diffuse large $B$ cell (DLBCL) } \\
\hline HIV-seronegative & $12 / 31$ & $<5-90$ & $1+$ to $3+$ \\
\hline HIV-seropositive (AIDS) & $1 / 1$ & 90 & $3+$ \\
\hline Lymphoplasmacytic lymphoma & $0 / 3$ & 0 & 0 \\
\hline Plasma cell myeloma & $0 / 3$ & 0 & 0 \\
\hline \multicolumn{4}{|c|}{ Heterogeneous/uncertain derived B cell lymphoma } \\
\hline SLL (60\% pre-GC, $40 \%$ post-GC) & $10 / 11$ & $10-70$ & $1+$ to $3+$ \\
\hline AIDS PEL & $0 / 2$ & 0 & 0 \\
\hline \multicolumn{4}{|l|}{ T cell lymphoma } \\
\hline Anaplastic large T cell & $0 / 1$ & 0 & 0 \\
\hline Cutaneous T cell & $0 / 4$ & 0 & 0 \\
\hline Mycosis fungoides & $0 / 2$ & 0 & 0 \\
\hline Peripheral large T cell & $0 / 4$ & 0 & 0 \\
\hline T/NK & $0 / 2$ & 0 & 0 \\
\hline \multicolumn{4}{|l|}{ Hodgkin disease } \\
\hline NLPHD, NSHD & $0 / 10$ & 0 & 0 \\
\hline
\end{tabular}

SLL, small lymphocytic lymphoma; PEL, primary effusion Iymphoma; T/NK, natural killer cell, T cell type; NLPHD, nodular, lymphocyte-predominant Hodgkin disease; NSHD, nodular sclerosing Hodgkin disease.

${ }^{a}$ Formalin-fixed, paraffin-embedded tissues were stained with Tcl1 antisera by immunohistochemical methods as previously described (Said et al, 1997, 1998; Teitell et al, 1999). Cell staining intensity was scored visually from $1+$ to $3+$ (see Fig. 3 for examples). Grouping of B cell lymphoma origins was based on published reports (Kuppers et al, 1999). SLL are considered both pre- and post-GC in derivation. The histogenesis of AIDS PEL is not fully resolved (Matolcsy et al, 1998).

Tcl1-positive. Three cases of pre-B lymphoblastic lymphoma strongly expressed Tcl1, consistent with earlier results showing that $\mathrm{Tcl} 1$ is highly expressed in pre-B and immature B lymphocytes (Virgilio et al, 1994). If cases with less than $10 \%$ of cells staining for Tcl1 are considered negative, due to potential residual or infiltrating normal B lymphocytes, then the number of post-GC positive cases drops to 10 of 41 (24\%), whereas the number of naïve/GC positive cases remains the same. The expression of Tcl1 is statistically different between GC and post-GC derived B cell lymphomas in immune-competent individuals $(p<$ 0.001). Finally, one post-GC AIDS-DLBCL patient sample stained strongly $(3+)$ for Tcl1 and was not included in these figures. If this case is added to previously reported results on TCL1 expression in systemic AIDS-DLBCL, then 7 of 9 (78\%) such cases now surveyed express TCL1 (Teitell et al, 1999).

\section{Tcl1 and Bcl-6 Expression Patterns Are Similar in DLBCL} from Patient Samples

Bcl-6 normally is expressed in GC B cells but not in post-GC B cells, whereas Tcl1 is expressed from early $B$ cell development in the bone marrow through GC stages of development (Cattoretti et al, 1995; Onizuka et al, 1995). Although distinct, these expression patterns are similar in that a concordant down-regulation of expression of these two oncoproteins occurs in post-GC B cells. To investigate the persistence of a concordant Tcl1 and Bcl-6 expression pattern in post-GC B cell tumors, 10 DLBCL (five Tcl1+ and five Tcl1-) were selected and stained with Bcl-6 antibody. As summarized in Table 3,2 of 10 (20\%) cases expressed Bcl- 6 but not Tcl1, whereas 3 of $10(30 \%)$ expressed neither, and 5 of $10(50 \%)$ expressed both oncoproteins. There were no cases in which Tcl1 was positive and Bcl-6 was negative. In those cases where both proteins were expressed, the proportion of tumor cells expressing $\mathrm{Bcl}-6$ was equivalent or higher than the proportion of tumor cells expressing Tcl1, whereas the levels of expression were often similar. These results show that $\mathrm{Tcl} 1$ and $\mathrm{Bcl}-6$ expression are concordant in 8 of $10(80 \%)$ DLBCL tested, which is consistent with the expression pattern of both genes in nonmalignant GC and post-GC B lymphocytes. However, concordant expression of these two oncoproteins does not necessarily indicate a mechanistic regulatory linkage between TCL 1 and BCL-6 oncogenes.

\section{Discussion}

In this study we have shown that the transition in Tcl1 expression that occurs in normal peripheral B lympho- 
Table 3. Relative Tcl1 Versus Bcl-6 Oncoprotein Expression Levels in DLBCL ${ }^{a}$

\begin{tabular}{|c|c|c|c|c|}
\hline Case No. & $\begin{array}{l}\text { Tumor Cells } \\
\text { Tcl1 }+(\%)\end{array}$ & $\begin{array}{l}\text { Level of Tcl1 } \\
\text { Expression }\end{array}$ & $\begin{array}{l}\text { Tumor Cells } \\
\mathrm{Bcl}-6+(\%)^{c}\end{array}$ & $\begin{array}{l}\text { Level of Bcl-6 } 6 \\
\text { Expression }\end{array}$ \\
\hline 1 & $<5$ & $1+$ & 60 & $1+$ to $3+$ \\
\hline 2 & 60 & $2+$ & 90 & $3+$ \\
\hline 3 & 0 & 0 & 95 & $3+$ \\
\hline 4 & $<10$ & $1+$ & 80 & $2+$ \\
\hline 5 & 0 & 0 & 30 & $2+$ \\
\hline 6 & 0 & 0 & 0 & 0 \\
\hline 7 & 40 & $1+$ & 70 & $2+$ \\
\hline $8(\operatorname{AIDS})^{d}$ & 60 & $2+$ & 80 & $3+$ \\
\hline 9 & 0 & 0 & 0 & 0 \\
\hline 10 & 0 & 0 & 0 & 0 \\
\hline 11 & 10 & $1+$ & 90 & $3+$ \\
\hline
\end{tabular}

${ }^{a}$ Formalin-fixed, paraffin-embedded tissues were stained with Tcl1 antisera and Bcl-6 antibody.

${ }^{b}$ Cell staining intensity was scored from $1+$ to $3+$.

${ }^{c}$ Bcl-6 staining was performed on five Tcl1+ and five Tcl1- cases due to tissue availability.

${ }^{d}$ Case 8 is from a patient with an AIDS-DLBCL.

cyte development usually is maintained in B cell lines and $B$ lymphoma patient samples derived from different stages of B cell maturation. However, this correlation is not maintained for AIDS-DLBCL, because our data show that a markedly higher proportion of AIDSDLBCL expressed Tcl1 than did DLBCL from immunecompetent individuals. We also observed a concordant expression pattern between Tcl1 and Bcl-6 oncoproteins in a majority of DLBCL patient samples tested. In contrast to previous results, we found no association between Tcl1 expression and EBV involvement in BL cell lines and we showed that functional maturity of the immune system is unimportant for peripheral Tcl1 expression. Finally, we demonstrated that PEL resemble myelomas in their lack of Tcl1 expression. Our findings suggest a useful role for Tcl1 detection in determining the developmental derivation of mature, peripheral $B$ cell lymphomas, except in AIDS-DLBCL where discordant expression has a potential etiologic role.

TCL1 expression did not differ significantly in three paired samples of EBV-positive and negative BL cell lines and expression was consistently present at high levels in EBV-immortalized PBC and fetal cord cells. MACS sorting results presented here, combined with earlier immunohistochemical results, clearly show that Tcl1 levels reflect the stage of development of B cells in peripheral lymphoid tissues, with expression declining in GC B cells from a peak in noncycling mantle zone $B$ cells to no expression in post-GC B cells. This same pattern of expression also is seen in $B$ cell lymphomas from immune-competent individuals. However, about $25 \%$ of those with DLBCL still express Tcl1, suggesting perhaps that either these DL$\mathrm{BCL}$ derive from GC B-like cells (see below) or that in one-quarter of DLBCL samples Tcl1 expression is dysregulated by an unknown mechanism. In contrast to DLBCL, TCL1 expression in AIDS-DLBCL persists, suggesting that either down-regulation of TCL1 is dependent on normal immune functions and that TCL1 is expressed aberrantly in the majority of AIDS-
DLBCL or that, unlike DLBCL, most AIDS-DLBCL derive from GC B-like cells.

Recently, a new approach for classifying DLBCL was reported (Alizadeh et al, 2000). A model was proposed for the developmental origins of DLBCL based on gene chip expression profiling. Tcl1 expression by immunohistochemistry in 31 independent DL$\mathrm{BCL}$ samples shown here is strikingly consistent with the TCL1 results obtained for 46 different DLBCL by gene profiling. We find 12 of 31 (39\%) (or 8 of 31 [26\%] if cases with less than 10\% Tcl1-positive cells are considered as negative) of DLBCL express Tcl1, whereas the gene profiling study detected 14 of 46 (30\%) of the DLBCL samples expressed TCL1 above a pooled sample background. However, gene profiling is unable to detect variable levels of expression of TCL1 within tumor and normal cells of a given sample, whereas our study demonstrates a wide range of Tcl1 expression in cells from different samples. One disadvantage of gene profiling is that the averaging of marker gene expression within a given sample can mask the sample extremes.

From gene profiling, DLBCL can be divided into two subgroups: GC B-like DLBCL and activated B-like DLBCL (Alizadeh et al, 2000). One of the key markers used to divide tumors into these two subgroups is $B C L-6$. Our results show several distinct patterns of Tcl1 and Bcl-6 expression in DLBCL. The lack of expression of both Tcl1 and Bcl-6 suggests a postGC, preterminal differentiation stage of derivation, whereas the coexpression of both proteins is consistent with a GC derivation. However, it must be noted that the patterns of expression for Tcl1 and Bcl-6 in GC are distinct, with Bcl-6 staining almost all GC cells and Tcl1 staining decreased from high levels in the mantle zone to low levels in most GC cells. The observation that some tumors express Bcl- 6 and not Tcl1 suggests a potential intermediate cell derivation, possibly from a unique Bcl-6 positive, Tcl1 negative GC cell stage of development. Alternatively, perhaps this pattern represents an aberration in the normal 
expression of one of these two genes caused by the tumorigenic process. Interestingly, when the gene expression profiles for BCL-6 and TCL1 are compared, it appears that $T C L 1$ may be superior to $B C L-6$ for distinguishing naïve (high), GC (low), and post-GC (negative) stages of B lymphoma derivation (Alizadeh et al, 2000). Tcl1 immunohistochemistry clearly provides a useful tool to delineate naïve/GC from post-GC B cell lymphomas in immune-competent individuals and may augment subclassification based on Bcl-6 reactivity. The dissection of DLBCL into Tcl1 positive and negative categories may also have important implications for the biology and treatment of this aggressive lymphoma subtype.

In this and an earlier study, we have shown that the percentage of AIDS-DLBCL expressing TCL1 (7 of 9, $78 \%$ ) more closely resembles the percentage of naïve/GC lymphomas that express Tcl1 (23 of 27, $85 \%)$ than the proportion of DLBCL expressing Tcl1 from immune-competent individuals (12 of $31,37 \%$, or 8 of $31,26 \%)$. This occurrence may explain the ease of originally isolating the TCL1 oncogene with subtractive techniques because there appears to be a significant difference in expression between AIDSDLBCL and DLBCL patient tumor samples (Teitell et al, 1999). This difference may reflect the disruption of normal lymphoid architecture present in late-stage AIDS patients (reviewed in Gaidano et al, 1998; Hamilton-Dutoit et al, 1991; Herndier et al, 1994; Knowles, 1997; Raphael et al, 1991, 1994). Interestingly, two recent studies disagree on the proportion of DLBCL from immune-competent patients that express Tcl1 (Nakayama et al, 2000; Narducci et al, 2000). One study showed $18 \%$, the other showed $60 \%$, of DLBCL expressed Tcl1. Our results support the lower figure in DLBCL from immune-competent individuals and the higher figure in immune-deficient patients. Explanations for this discrepancy might include differential application of the criteria used to diagnose DLBCL because of tumor heterogeneity or unknown influences from distinct patient populations. DLBCL are a heterogeneous group with variable treatment outcomes and prognoses, and the heterogeneity in Tcl1 expression demonstrated here may have clinical relevance. Moreover, the relatively high proportion of immune-deficient AIDS-DLBCL that express Tcl1 compared with immune-competent DLBCL may have a bearing on the pathogenesis of these neoplasms.

PEL and myeloma have in common a complete lack of Tcl1 expression in all cell lines and patient samples examined thus far. The derivation of myeloma from an end-stage B-lineage plasma cell is well documented. However, there is no consensus on the stage or stages of $B$ cell development that give rise to PEL in immune-compromised individuals (Matolcsy et al, 1998). Our finding of complete absence of Tcl1 in PEL adds some support to an origin from post-GC through terminally differentiated B lymphocytes, similar to myeloma. In this regard, the BC-3 PEL line stands out as a possible exception to this hypothesis because it is considered to arise from a pre-GC stage of development due to a lack of somatic hypermutation. How- ever, BC-3 expresses multiple late lymphocyte activation and adhesion markers, including CD30, CD38, CD138, HLA-DR, and CD54, which is consistent with a GC or post-GC derivation (Drexler et al, 1998). It appears, therefore, that most PEL derive from GC or post-GC B cell precursors.

\section{Materials and Methods}

\section{EBV Immortalization and Cell Culture}

Peripheral blood lymphocytes and fetal cord cells were harvested from HIV-seronegative individuals and immortalized by incubation with supernatant from the EBV-producing marmoset cell line B95-8 according to standard protocols (Miller and Lipman, 1973; Miller et al, 1974; Ounanian et al, 1992). All cell lines, except $\mathrm{PEL}$ lines, were maintained at $37^{\circ} \mathrm{C}$ in $5 \% \mathrm{CO}_{2}$ and grown in RPMI 1640 medium supplemented with $2 \mathrm{~mm}$ L-glutamine and 10\% FBS. The PEL lines were grown in medium containing $20 \%$ serum. EBV-immortalized cell lines were weaned from $20 \%$ to $10 \%$ FBS after cell line expansion. Cell lines were provided as kind gifts from Drs. B. Bonavida (2F7 and R), S. PlaegerMarshall (immortalized fetal cord and PBC lines), O. Martinez-Maza (P3HR-1), and R. Sun (BL41, BL41/ B95-8, BJAB, and BJAB-B1; University of California at Los Angeles School of Medicine, Los Angeles, California) and from Dr. J. T. Sample (Akata A1.5, Akata 2A8, and Akata 3F2; University of Tennessee Health Sciences Center, Memphis, Tennessee).

\section{Northern Blot Analysis}

Total cellular RNA was isolated (Rneasy Mini Kit; Qiagen, Santa Clarita, California) and $10 \mu \mathrm{g}$ per sample was size-fractionated on a $1 \%$ denaturing formaldehyde gel. Size-fractionated RNA was transferred to a nitrocellulose membrane (Nitroplus; MSI, Westborough, Massachusetts) in 10× SSC and fixed in place by baking at $80^{\circ} \mathrm{C}$ for 1 hour in a vacuum oven. Fifty nanograms of a 350-bp human TCL1 cDNA fragment were random-primed (Prime-It II; Stratagene, La Jolla, California) with $\alpha-\mathrm{P}^{32}$ dATP for use as a probe. Membranes were prehybridized at $42^{\circ} \mathrm{C}$ for 2 to 4 hours in Denhardt's solution containing $2.5 \mathrm{mg}$ boiled herringsperm DNA, and then hybridized with $10^{6}$ counts $/ \mathrm{ml}$ radiolabeled $T C L 1$ probe at $42^{\circ} \mathrm{C}$ overnight. Hybridized membranes were washed stringently (final wash: $0.1 \times \mathrm{SSC} / 0.1 \%$ SDS, 30 minutes, $52^{\circ} \mathrm{C}$ ) and TCL 1 RNA was detected by autoradiography and by Phosphorimager analysis with the ImageQuant program (Molecular Dynamics, Sunnyvale, California). Equal RNA loading was assured by ultraviolet visualization of ethidium bromide stained gels (Fig. 1).

\section{Patient Tumor Samples and Immunohistochemistry}

Malignant lymphomas were characterized by immunophenotype, classified according to the World Health Organization classification system, and retrieved from the files of the surgical pathology division of the Anatomic Pathology Department at University of Cal- 
ifornia at Los Angeles (Harris et al, 1997). Serial paraffin sections were stained with Tcl1 antisera and Bcl-6 antibodies (DAKO, Carpinteria, California) using immunoperoxidase techniques as previously described (Said et al, 1997, 1998; Teitell et al, 1999). Results were interpreted according to the percentage of neoplastic cells staining positive for Tcl1 or Bcl-6 together with the intensity of staining (1 to $3+$ ). Negative controls consisted of substituting the primary Tcl1 antisera with preimmune serum or substituting the primary $\mathrm{Bcl}-6$ antibody with a non-cross-reactive isotype-specific monoclonal antibody. Positive controls, consisting of sections of hyperplastic tonsil, were run with all cases. Fresh-frozen cell line pellets were stained for TCL1 expression by a similar immunoperoxidase technique (not shown).

\section{B Lymphocyte Fractionation from Human Tonsil}

Hyperplastic tonsils were obtained from the Human Tissue Resource Center at University of California at Los Angeles with strict adherence to established guidelines for the protection of human subjects (IRB). $B$ cell subsets were then isolated as previously described (Babcock and Thorley-Lawson, 2000). Tonsils were minced under sterile conditions in $1 \times \mathrm{PBS}(\mathrm{pH}$ 7.4, 1\% BSA, and 5 mm EDTA) and passed through a 40- $\mu \mathrm{m}$ filter to remove connective tissue and debris. Viable lymphocytes were isolated by centrifugation on a Ficoll-Paque Plus cushion (Amersham Pharmacia Biotech, Piscataway, New Jersey), followed by washing in PBS. B cells were fractionated using a MACS system (Miltenyi Biotec, Auburn, California) according to the manufacturer's instructions. Isolated populations were analyzed by flow cytometry to determine percentage purity. Naïve B cells (CD3-/lgD+) were isolated by negative selection with anti-CD3 antibody (FITC-CD3, clone S4.1; BD PharMingen, San Diego, California) followed by MACS positive selection with anti-IgD antibody (R-PE-IgD, clone 1A6-2; BD PharMingen) to more than $90 \%$ purity. GC B cells (CD3-/ CD10+/lgD-) were isolated by MACS negative selection with anti-CD3 antibody (R-PE-CD3, clone 5-1B4; Caltag, Burlingame, California) and anti-IgD antibody (BD PharMingen), followed by MACS positive selection with anti-CD10 antibody (R-PE-CD10, clone 5-1B4; Caltag) to more than $85 \%$ purity. Memory B cells (CD3-/CD10-/lgD-) were isolated by MACS negative selection with anti-CD3 antibody (Caltag) and anti-IgD antibody (BD PharMingen), followed by MACS negative selection with anti-CD10 antibody (Caltag) to more than 95\% purity. Memory B cells were verified by additional staining and flow cytometry with anti-CD19 antibody (FITC-CD19, leu-12; BD PharMingen) and anti-CD20 antibody (FITC-CD20, leu-16; BD PharMingen). Plasma cells (CD3-/CD138+) were isolated as previously described (Jego et al, 1999) by MACS negative selection with anti-CD3 antibody (BD PharMingen) followed by MACS positive selection with anti-CD138 antibody (R-PE-CD138, clone BB4; BD PharMingen).

\section{In Vitro Generation of Plasmacytoid B Cells}

Plasmacytoid B cells were generated as previously described (Fluckiger et al, 1998). Briefly, after tonsil disruption and Ficoll-Paque Plus centrifugation, B lymphocytes were positively selected with anti-CD19 microbeads (Miltenyi Biotec) using MACS. Isolated CD19+ B cells $\left(8 \times 10^{5}\right.$ cells/well $)$ then were incubated in 12-well tissue culture plates on irradiated (8,000 rad) CD40L-expressing $L$ cell fibroblasts (approximately $60 \%$ confluent) in RPMI 1640 medium containing $20 \%$ FCS, 20 ng/ml IL4, 20 ng/ml IL10, and antibiotics. IL4 and IL10 were resupplemented on Day 4 of culture. After one week, cells were harvested and analyzed by anti-Tcl1 Western blot and plasmacytoid features confirmed with Wright-Giemsa staining of cytospin pellets.

\section{Anti-Tcl1 Western Blot Analysis}

Fractionated $B$ cells were washed twice with PBS then lysed in NP-40 lysis buffer (50 mm Tris, pH 7.6, 300 mm $\mathrm{NaCl}, 0.5 \% \mathrm{NP}-40,10 \%$ glycerol, 1 mm EDTA, and protease inhibitors) and centrifuged at $15,000 \times g$ for 20 minutes at $4^{\circ} \mathrm{C}$. Protein concentrations were determined using the Bio-Rad protein assay (Bio-Rad, Hercules, California). P3HR-1 cell lysates were used as a Tcl1-positive control and BCBL-1 cell lysates were used as a negative control. Six micrograms of total protein for each sample was separated by $15 \%$ SDS PAGE and transferred to a nitrocellulose membrane (Micron Separations, Westborough, Massachusetts). The membrane was blocked in Tris buffered saline plus Tween (TBST, TBS, and $0.1 \%$ Tween) and $5 \%$ dry milk for 15 minutes. The membrane then was incubated with Tcl1 antisera (Teitell et al, 1999) in TBST (diluted 1:7,500) for 1 hour, then washed for 3 minutes 6 times in TBST. After this, the filter was incubated in antirabbit IgG HRP-linked antisera (New England Biolabs, Beverly, Massachusetts) in TBST (diluted 1:5,000) for 1 hour, followed by 6 washes in TBST and developed with ECL+Plus (Amersham Pharmacia Biotech). Densitometric analysis was performed using the Chemilmager 5500 with AlphaEaseFC software (Alpha Innotech, San Leandro, California).

\section{Statistical Analysis}

The null hypothesis, that $\mathrm{Tcl} 1$ expression is equivalent in naïve/GC and in post-GC-derived B cell lymphomas, was evaluated with a two-sample proportion test.

\section{Acknowledgement}

We thank Stephen G. Teitell for assistance with statistical analysis.

\section{References}

Alizadeh AA, Eisen MB, Davis RE, Ma C, Lossos IS, Rosenwald A, Blodrick JC, Sabet H, Tran T, Yu X, Powell Jl, Yang L, Marti GE, Moore T, Hudson J, Lu L, Lewis DB, Tibshirani R, 
Sherlock G, Chan WC, Greiner TC, Weisenburger DD, Armitage JO, Warnke R, Levy R, Wilson W, Grever MR, Byrd JC, Botstein, D, Brown PO, and Staudt LM (2000). Distinct types of diffuse large B-cell lymphoma identified by gene expression profiling. Nature 403:503-511.

Babcock GJ and Thorley-Lawson DA (2000). Tonsillar memory B cells, latently infected with Epstein-Barr virus, express the restricted pattern of latent genes previously found only in Epstein-Barr virus-associated tumors. Proc Natl Acad Sci USA 97:12250-12255.

Benjamin D, Magrath IT, Maguire R, Janus C, Todd HD, and Parsons RG (1982). Immunoglobulin secretion by cell lines derived from African and American undifferentiated lymphomas of Burkitt's and non-Burkitt's type. J Immunol 129:1293-1336.

Cattoretti G, Chang CC, Cechova K, Zhang J, Ye BH, Falini B, Louie DC, Offit K, Chaganti RS, and Dalla-Favera R (1995). BCL-6 protein is expressed in germinal-center $B$ cells. Blood 86:45-53.

Davey MP, Bertness V, Nakahara K, Johnson JP, McBride OW, Waldmann TA, and Kirsch IR (1988). Juxtaposition of the T-cell receptor alpha-chain locus (14q11) and a region (14q32) of potential importance in leukemogenesis by a 14;14 translocation in a patient with T-cell chronic lymphocytic leukemia and ataxia-telangiectasia. Proc Natl Acad Sci USA 85:9287-9291.

Demidem A, Salahuddin Z, Lam T, Levine AM, Khan RS, Hober D, and Bonavida B (1996). Sensitization of AIDS related non-Hodgkin's B lymphoma cell lines to cytotoxic drugs/toxins by interferon gamma. Intl J Oncol 8:461-468.

Drexler HG, Uphoff CC, Gaidano G, and Carbone A (1998). Lymphoma cell lines: In vitro models for the study of HHV-8+ primary effusion lymphomas (body cavity-based lymphomas). Leukemia 12:1507-1517.

Fluckiger A-C, Sanz E, Garcia-Lloret M, Su T, Hao Q-L, Kato R, Quan S, de la Hera A, Crooks GM, Witte ON, and Rawlings DJ (1998). In vitro reconstitution of human B-cell ontogeny: From CD34+ multipotent progenitors to lg-secreting cells. Blood 92:4509-4520.

Gaidano G, Carbone A, and Dalla-Favera R (1998). Pathogenesis of AIDS-related lymphomas: Molecular and histogenetic heterogeneity. Am J Pathol 152:623-630.

Hamilton-Dutoit SJ, Pallesen G, Franzmann MB, Karkov J, Black F, Skinhoj P, and Pedersen C (1991). AIDS-related lymphoma: Histopathology, immunophenotype, and association with Epstein-Barr virus as demonstrated by in situ nucleic acid hybridization. Am J Pathol 138:149-163.

Harris NL, Jaffe ES, Diebold J, Flandrin G, Muller-Hermelink HK, Vardiman J, Lister A, and Bloomfield CD (1997). World Health Organization classification of neoplastic diseases of the hematopoietic and lymphoid tissues: Report of the Clinical Advisory Committee meeting, Airlie House, Virginia, November 1997. J Clin Oncol 17:3835-3849.

Herndier BG, Kaplan LD, and McGrath MS (1994). Pathogenesis of AIDS lymphomas. Aids 8:1025-1049.

Hummel M, Tamaru J, Kalvelage B, and Stein H (1994). Mantle cell (previously centrocytic) lymphomas express $\mathrm{VH}$ genes with no or very little somatic mutations like the physiologic cells of the follicle mantle. Blood 84:403-407.

Jego G, Robillard N, Puthier D, Amiot M, Accard F, Pineau D, Harousseau JL, Bataille R, and Pellat-Deceunynck C (1999). Reactive plasmacytoses are expansions of plasmablasts retaining the capacity to differentiate into plasma cells. Blood 94:701-712.

Jones D, Ballestas ME, Kaye KM, Gulizia JM, Winters GL, Fletcher J, Scadden DT, and Aster JC (1998). Primaryeffusion lymphoma and Kaposi's sarcoma in a cardiactransplant recipient. N Engl J Med 339:444-449.

Knowles DM (1997). Molecular pathology of acquired immunodeficiency syndrome-related non-Hodgkin's lymphoma. Semin Diagn Pathol 14:67-82.

Kuppers R, Klein U, Hansmann ML, and Rajewsky K (1999). Cellular origin of human B-cell lymphomas. N Engl $\mathrm{J}$ Med 341:1520-1529.

Laine J, Kunstle G, Obata T, Sha M, and Noguchi M (2000). The protooncogene TCL1 is an Akt kinase coactivator. Mol Cell 6:395-407.

Matolcsy A, Nador RG, Cesarman E, and Knowles DM (1998). Immunoglobulin $\mathrm{VH}$ gene mutational analysis suggests that primary effusion lymphomas derive from different stages of $B$ cell maturation. Am J Pathol 153:1609-1614.

Mengle-Gaw L, Albertson DG, Sherrington PD, and Rabbitts TH (1988). Analysis of a T-cell tumor-specific breakpoint cluster at human chromosome 14q32. Proc Natl Acad Sci USA 85:9171-9175.

Miller G and Lipman M (1973). Release of infectious EpsteinBarr virus by transformed marmoset leukocytes. Proc Natl Acad Sci USA 70:190-194.

Miller G, Robinson J, Heston L, and Lipman M (1974). Differences between laboratory strains of Epstein-Barr virus based on immortalization, abortive infection, and interference. Proc Natl Acad Sci USA 71:4006-4010.

Nakayama I, Murao S, Kitazawa S, Azumi A, Yamamoto M, and Maeda S (2000). Activation of the TCL1 protein in B cell lymphomas. Pathol Int 50:191-199.

Narducci MG, Pescarmona E, Lazzeri C, Signoretti S, Lavinia AM, Remotti D, Scala E, Baroni CD, Stoppacciaro A, Croce CM, and Russo G (2000). Regulation of TCL1 expression in $\mathrm{B}-$ and T-cell lymphomas and reactive lymphoid tissues. Cancer Res 60:2095-2100.

Onizuka T, Moriyama M, Yamochi T, Kuroda T, Kazama A, Kanazawa N, Sato K, Kato T, Ota H, and Mori S (1995). BCL-6 gene product, a 92- to 98-kD nuclear phosphoprotein, is highly expressed in germinal center B cells and their neoplastic counterparts. Blood 86:28-37.

Ounanian A, Guilbert B, and Seigneurin JM (1992). Characteristics of Epstein-Barr virus transformed B cell lines from patients with Alzheimer's disease and age-matched controls. Mech Ageing Dev 63:105-116.

Pekarsky Y, Hallas C, Isobe M, Russo G, and Croce CM (1999). Abnormalities at $14 \mathrm{q} 32.1$ in $\mathrm{T}$ cell malignancies involve two oncogenes. Proc Natl Acad Sci USA 96:2949-2951.

Pekarsky Y, Koval A, Hallas C, Bichi R, Tresini M, Malstrom S, Russo G, Tsichlis P, and Croce CM (2000). Tcl1 enhances Akt kinase activity and mediates its nuclear translocation. Proc Natl Acad Sci USA 97:3028-3033.

Raphael M, Gentilhomme O, Tulliez M, Byron PA, and Diebold J (1991). Histopathologic features of high-grade non-Hodgkin's lymphomas in acquired immunodeficiency syndrome. The French Study Group of Pathology for Human Immunodeficiency Virus-Associated Tumors. Arch Pathol Lab Med 115:15-20. 
Raphael MM, Audouin J, Lamine M, Delecluse HJ, Vuillaume M, Lenoir GM, Gisselbrecht C, Lennert K, and Diebold J (1994). Immunophenotypic and genotypic analysis of acquired immunodeficiency syndrome-related non-Hodgkin's lymphomas: Correlation with histologic features in 36 cases. French Study Group of Pathology for HIV-Associated Tumors. Am J Clin Pathol 101:773-782.

Ruf IK, Rhyne PW, Yang H, Borza CM, Hutt-Fletcher LM, Cleveland JL, and Sample JT (1999). Epstein-Barr virus regulates c-myc, apoptosis, and tumorigenicity in Burkitt lymphoma. Mol Cell Biol 19:1651-1660.

Russo G, Isobe M, Pegoraro L, Finan J, Nowell PC, and Croce CM (1988). Molecular analysis of a $t(7 ; 14)(q 35 ; q 32)$ chromosome translocation in a $\mathrm{T}$ cell leukemia of a patient with ataxia telangiectasia. Cell 53:137-144.

Said JW, Pinkus JL, Yamashita J, Mishalani S, Matsumura F, Yamashiro S, and Pinkus GS (1997). The role of follicular and interdigitating dendritic cells in HIV-related lymphoid hyperplasia: Localization of fascin. Mod Pathol 10:421-427.

Said JW, Pinkus JL, Shintaku IP, deVos S, Matsumura F, Yamashiro S, and Pinkus GS (1998). Alterations in fascinexpressing germinal center dendritic cells in neoplastic follicles of B-cell lymphomas. Mod Pathol 11:1-5.

Shou Y, Martelli ML, Gabrea A, Qi Y, Brents LA, Roschke A, Dewald G, Kirsch IR, Bergsagel PL, and Kuehl WM (2000). Diverse karyotypic abnormalities of the c-myc locus associate. Proc Natl Acad Sci USA 96:9809-9814.
Takizawa J, Suzuki R, Kuroda H, Utsuomiya A, Kagami Y, Joh T, Aizawa Y, Ueda R, and Seto M (1998). Expression of the TCL1 gene at 14q32 in B-cell malignancies but not in adult T-cell leukemia. Jpn J Cancer Res 89:712-718.

Teitell M, Damore MA, Sulur GG, Turner DE, Stern M-H, Said JW, Denny CT, and Wall R (1999). TCL1 oncogene expression in AIDS-related lymphomas and lymphoid tissues. Proc Natl Acad Sci USA 96:9809-9814.

Virgilio L, Isobe M, Narducci MG, Carotenuto P, Camerini B, Kurosawa N, Rushdi A, Croce CM, and Russo G (1993). Chromosome walking on the TCL1 locus involved in T-cell neoplasia. Proc Natl Acad Sci USA 90:9275-9279.

Virgilio L, Narducci MG, Isobe M, Billips LG, Cooper MD, Croce CM, and Russo G (1994). Identification of the TCL1 gene involved in T-cell malignancies. Proc Natl Acad Sci USA 91:12530-12534.

Westphal EM, Mauser A, Swenson J, Davis MG, Talarico CL, and Kenney SC (1999). Induction of Iytic Epstein-Barr virus (EBV) infection in EBV-associated malignancies using adenovirus vectors in vitro and in vivo. Cancer Res 59:1485-1491. 